\title{
Novel functional copolymers based on glycidyl methacrylate: Synthesis, characterization, and polymerization kinetics
}

\author{
Ibrahim Erol, Derya Nimet Devrim, Hakan Ciftci, Bahri Ersoy \& I. Hakkı \\ Cigerci
}

To cite this article: Ibrahim Erol, Derya Nimet Devrim, Hakan Ciftci, Bahri Ersoy \& I. Hakkı Cigerci (2017) Novel functional copolymers based on glycidyl methacrylate: Synthesis, characterization, and polymerization kinetics, Journal of Macromolecular Science, Part A, 54:7, 434-445, DOI: 10.1080/10601325.2017.1320747

To link to this article: http://dx.doi.org/10.1080/10601325.2017.1320747

Published online: 12 Jul 2017.

Submit your article to this journal

View related articles $\sqsubset$

View Crossmark data $\nearrow$ 


\title{
Novel functional copolymers based on glycidyl methacrylate: Synthesis, characterization, and polymerization kinetics
}

\author{
Ibrahim Erol ${ }^{a}$, Derya Nimet Devrim ${ }^{a}$, Hakan Ciftci $^{b}$, Bahri Ersoy $^{b}$ and I. Hakkı Cigerci ${ }^{c}$

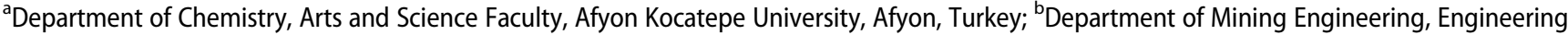 \\ Faculty, Afyon Kocatepe University, Afyon, Turkey; ${ }^{C}$ Department of Molecular Biology and Genetics, Arts and Science Faculty, Afyon Kocatepe \\ University, Afyon, Turkey
}

\begin{abstract}
A new methacrylate monomer 2-(4-nitrophenyl)-2-oxoethyl-2-methacrylate (NFM) was synthesized and its radical copolymerization with glycidyl methacrylate (GMA) was studied in 1,4-dioxane solution at $65^{\circ} \mathrm{C}$ using 2,2'-azobisisobutyronitrile as an initiator. The synthesized monomer and copolymers were characterized by FTIR, ${ }^{1} \mathrm{H}$ and ${ }^{13} \mathrm{C}$-NMR spectroscopy. The analysis of reactivity ratios revealed that NFM is less reactive than GMA, and copolymers formed are statistically in nature. Thermogravimetric analysis of the polymers reveals that the thermal stability of the copolymers increases with an increasing in the mole fraction of NFM in the copolymers. Glass transition temperatures of the copolymers decreased with an increasing of NFM molar fraction in copolymers. In addition, according to the results obtained from the contact angle and zeta potential measurements the hydrophobic character of the polymer decreases (it means surface free energy increases) and its zeta potential becomes more negative with increase of NFM ratio in the copolymer. Polymers with carbonyl functional groups have been particularly interesting because of their use as photoresists.
\end{abstract}

\section{ARTICLE HISTORY}

Received November 2016

Revised and Accepted

December 2016

\section{KEYWORDS}

Biological activity; glicidyl methacrylate; monomer reactivity ratios; thermal stability; zeta potential

\section{Introduction}

Polymethacrylates with keto side chains have attracted increasing interest $(1,2)$. Polymers with carbonyl functional groups have been particularly interesting because of their use as photoresists to make large-scale integrated circuits, printing plates, photocurable coatings $(3,4)$, photoconductors (5), energyexchange materials (6), enzyme fixing materials (7), protecting groups in organic syntheses (8), and photosensitizers (9) of organic syntheses (10). Acrylate and methacrylate polymers have figured prominently in the development of soft-tissuecompatible materials (11) and orthopedic (12) and dental cements (13).

Polymer supports based on glycidyl methacrylate are mainly used as excellent thermosetting adhesives that have gained popularity over the years because of their superior performance in many applications such as binding of drugs and biomolecules (14) and in electron industries as negative electron beam resists (15). Copolymers of glycidyl methacrylate have received significant attention due to the pendent epoxide groups which enter into a large number of chemical reactions $(16,17)$, thus offering the opportunity for chemical modification of the parent copolymers for various uses.

The concepts like hydrophobicity, surface free energy and zeta potential are in the most important surface characteristics of solids. These concepts are commonly encountered in several sectors like mining, textile, aviation, automotive, petroleum, paper, pharmaceutical, medical, plastic, paint, environment, food and metal (18-21). For instance, the hydrophobicity and surface free energy are significant to the production of composite materials with the polymeric warp, reinforced with fibres, which play a very important role in such vital areas as the automotive or aviation industries (22). Similarly in medical, knowing the zeta potential of the microfluidic devices such as chips produced from PMMA type polymeric material is important to examine their flowing behavior in blood (23). In all these sectors, the explanation of the mechanisms such as adhesion, coating, printing, deinking, lubrication, dispersion, flocculation can be possible with these concepts.

Knowledge of the copolymer composition is an important step in the evaluation of its utility. The copolymer composition and its distribution depend on monomer reactivity ratios. The most common mathematical model of copolymerization is based on finding the relationship between the composition of copolymers and the composition of the monomer feed in which the monomer-reactivity ratios are the parameters to be determined $(24,25)$. The calculation of the monomer -reactivity ratios requires the mathematical treatment of experimental data on the composition of copolymers and monomer in feed mixtures. Spectroscopic methods and elemental analysis are probably the most widely used methods for the analysis of copolymers and the determination of reactivity ratios $r_{1}$ and $r_{2}$.

NFM is also a new methacrylate monomer having pendant ketone and nitro group. In previous studies, the synthesis, characterization and copolymerization behavior of similarly 
monomers and their polymers have been described (26). GMA is very important commercial monomer for polymer chemistry. However, no studies on reactivity ratios in the copolymerizations of NFM with GMA appear in the literature. The present article devoted to the synthesis, structural, and thermal characterization of copolymers of NFM with GMA as well as the determination of reactivity ratios of monomers in the copolymerization.

\section{Experimental}

\subsection{Materials}

Glycidyl methacrylate (GMA) (Sigma) was each passed in turn through a basic alumina column in order to remove inhibitor. 4-nitro phenacyl bromide, sodium methacrylate, 1,4-dioxane, potassium carbonate, acetonitrile, and anhydrous magnesium sulphate (Aldrich) were used as received. 2,2'-Azobisisobutyronitrile was recrystallized from chloroform-methanol (V/V:1/1). Bactopeptone and glucose was obtained from Difco. All the other chemicals were analytical grade and used without any further purification.

\subsection{Microorganisms}

The test organisms for antimicrobial activity in the stady are Bacillus subtilis (NRS-744), Staphylococcus aureus ATCC 25923, Salmonella typhimurium (NRRLB-4420), Escherichia coli ATCC 25992, Listeria monocytogenes (ATCC 7644), Proteus vulgaris, Klebsiellapneumoniae, Enterecoccus fecalis (ATCC 29212), Yersinya and Micrococcus luteus.

\subsection{Characterization techniques}

FTIR spectra were measured in the range $400-4000 \mathrm{~cm}^{-1}$ on a Perkin-Elmer Spectrum BX FT-IR spectrometer with a $\mathrm{KBr}$ pellet. ${ }^{1} \mathrm{H}$ - and ${ }^{13} \mathrm{C}-\mathrm{NMR}$ spectra were recorded in $\mathrm{CDCl}_{3}$ with tetramethylsilane as the internal standard using a Bruker $\mathrm{GmbH}$ DPX-400 $400 \mathrm{MHz}$ spectrometer. The glass transition (Tg) temperatures were determined by DSC with a Shimadzu DSC60H. Samples of about 4-7 mg held in sealed aluminum crucibles first heating scan and the heating rate of $20^{\circ} \mathrm{C} / \mathrm{min}$ under a dynamic nitrogen flow $(5 \mathrm{l} / \mathrm{h})$ were used for the measurements. The thermal stabilities of the polymers were investigated by TGA with a Shimadzu TG60H in a nitrogen stream at a heating rate of $20^{\circ} \mathrm{C} \mathrm{min}^{-1}$. Molecular weight characteristicsof the polymers were determined by e waters $410 \mathrm{GPC}$ equipped with a differential RI detector and calibrated with polystyrene standards. Elemental analyses were carried out by a Elementar CHNSO auto microanalyzer

\subsection{Zeta potential measurement}

Prior to the zeta potential measurements each polymer sample were powdered in a muller and then sieved to under the particle size of $90 \mu \mathrm{m}$. Zeta potential measurements of the samples were then done. $0.05 \mathrm{~g}$ sample was put in $100 \mathrm{ml} 10^{-2} \mathrm{M} \mathrm{NaCl}$ solution and mechanically stirred $30 \mathrm{~min}$. The $\mathrm{pH}$ was then adjusted to the required value by using $0.01-5 \mathrm{M} \mathrm{HCl}$ and
0.01-1 $\mathrm{M} \mathrm{NaOH}$ solutions and stirred for a further $5 \mathrm{~min}$. Necessary amount of sample was taken from this suspension with the help of an injector and put into zeta-meter (Malvern Nano-Z) measurement cell. Then zeta potentials were measured at room temp. $\left(20 \pm 2^{\circ} \mathrm{C}\right)$ by electrophoretic mobility method. The iso electrical point (iep) of used polymer sample has been determined from the curve.

\subsection{Contact angle measurement and surface free energy determination}

Discs of polymer powder were prepared under $50 \mathrm{kN}$ before contact angle measurements by sessile drop method using an Attension Theta optical tensiometer. A $5 \mu \mathrm{L}$ drop of appropriate liquid (pure water, ethyleneglycol or di-iodiomethane) was placed on the disc shaped sample using a Hamilton injector. Afterwards, the liquid drop positioned on polymer surface were photographed totally 105 times in $5 \mathrm{sec}$ and contact angles were measured by digital goniometer. These procedure has been repeated for each of liquid at room temperature (20 \pm $2^{\circ} \mathrm{C}$ ). Then, surface free energy of the polymer was calculated according to Fowkes theory by using measured contact angle data and surface energy components of test liquids. This calculation was realized automatically with the help of the device software. The formulation recommended by Fowkes and used for calculation of surface energy is given below in Equation 1 (22). In the geometrical average theory recommended by Fowkes, solid's surface energy consists of the sum of two components which are dispersive $\left(\gamma^{\mathrm{d}}\right)$ and polar $\left(\gamma^{\mathrm{P}}\right)$ energy.

$$
\gamma_{\mathrm{L}}(1+\cos \theta)=2\left\lfloor\sqrt{\gamma_{\mathrm{L}}^{\mathrm{d}} \gamma_{\mathrm{S}}^{\mathrm{d}}}+\sqrt{\gamma_{\mathrm{L}}^{\mathrm{P}} \gamma_{\mathrm{S}}^{\mathrm{p}}}\right\rfloor
$$

where $\gamma_{S}$ is the surface free energy of solid, $\gamma_{\mathrm{L}}$ is the surface tension or energy of liquid, $\gamma_{\mathrm{L}}^{\mathrm{d}}$ is the dispersive energy of liquid, $\gamma_{S}^{\mathrm{d}}$ is the dispersive energy of solid, $\gamma_{\mathrm{L}}^{\mathrm{P}}$ is the polar energy of liquid and $\gamma_{S}^{p}$ is the polar energy of solid.

If we put the contact angles measured by two liquids whose surface tension components are known and surface tension componentsion Equation 1, then we get two equations with two unknowns. $\gamma_{S}^{\mathrm{p}}$ ve $\gamma_{S}^{\mathrm{d}}$ components of solid's surface energy and its total surface energy are found by solving these equations. All the units in the equation are given as $\mathrm{mJ} / \mathrm{m}^{2}$.

\subsection{Synthesis of NFM monomer}

The NFM monomer was synthesized as follows; $1 \mathrm{mmol}$ 4-nitro phenacyl bromide, $1.1 \mathrm{mmol}$ sodium methacrylate were stirred in $250 \mathrm{ml}$ acetonitrile at $75-8^{\circ} \mathrm{C}$ in a reflux condenser for $24 \mathrm{~h}$. Then mixture was cooled to room temperature, and the organic layer was washed several times with water, and the aqueous layer was washed with diethyl ether a few times. The acetonitrile layer and diethyl ether layer were collected and dried over anhydrous $\mathrm{MgSO}_{4}$ overnight. Acetonitrile and diethyl ether were then evaporated, and the resulting monomer purified by recrystallization from ethanol (yield $82 \%$ ). The monomer was examined by FT-IR and ${ }^{1} \mathrm{H}$ and ${ }^{13} \mathrm{C}$ - NMR spectroscopy. 
IR (KBr pellet), $\mathrm{cm}^{-1}$ : 3120 ( $\mathrm{Ar}-\mathrm{H}$ stretching), 1725 and $1734\left(\mathrm{C}=\mathrm{O}\right.$, ester and ketone carbonyl), $1630\left(-\mathrm{C}=\mathrm{CH}_{2}\right)$, $1254(\mathrm{C}-\mathrm{O}-\mathrm{C}), 1550\left(-\mathrm{NO}_{2}\right), 2960$ and 698. (Aliphatic $\left.\mathrm{C}-\mathrm{H}\right)$.

${ }^{1} \mathrm{H}-\mathrm{NMR}\left(\delta\right.$, ppm from TMS in $\left.\mathrm{CDCl}_{3}\right): 6.5-6.8$ (aromatic protons, $3 \mathrm{H}) ; 5.6\left(\mathrm{CH}_{2}=, 1 \mathrm{H}\right) ; 6.2\left(\mathrm{CH}_{2}=, 1 \mathrm{H}\right) ; 1.9\left(\mathrm{CH}_{3-}\right.$, $3 \mathrm{H}), 5.4\left(\mathrm{OCH}_{2}\right)$.

${ }^{13} \mathrm{C}-\mathrm{NMR}\left(\delta\right.$, ppm from TMS in $\left.\mathrm{CDCl}_{3}\right): 192.0(\mathrm{C}=\mathrm{O}$ of ketone); and 168 ( $\underline{\mathrm{C}}=\mathrm{O}$ of ester); $138.0(=\underline{\mathrm{C}}) ; 124.1\left(\underline{\mathrm{CH}_{2}}=\right)$ ); 124-140 (Ar-C); $68\left(\mathrm{OCH}_{2}\right) ; 18\left(\mathrm{CH}_{3}\right.$ in olefinic carbon).

\subsection{Homopolymerization}

1 gram of monomer NFM and $50 \mathrm{mg}$ of AIBN free radical initiator were dissolved in $10 \mathrm{ml}$ of 1,4-dioxane in a polymerization tube and oxygen free nitrogen was purged through a solution for $10 \mathrm{~min}$. Then the solution was thermostated at $65^{\circ} \mathrm{C}$. After $24 \mathrm{~h}$, the polymer was precipitated in ethanol. By repeated reprecipitation by ethanol from chloroform solution the polymer was reprecipitated. The polymer was then dried in vacuum at $50^{\circ} \mathrm{C}$ for $24 \mathrm{~h}$.

\subsection{Copolymerization}

Copolymerization of NFM with GMA (Scheme 1) using different feed ratio was carried out in glass ampoules under $\mathrm{N}_{2}$ atmosphere in 1,4-dioxane solution with AIBN (1 wt\% with respect to the total monomer weight) at constant monomer concentration $(2 \mathrm{~mol} / \mathrm{L})$ in an oil bath at $65 \pm 0.1^{\circ} \mathrm{C}$ for a given reaction time. The reaction time was selected to give conversions less than $10 \%$. After the desired time the copolymers were extracted by precipitation in ethanol and reprecipitated from $\mathrm{CH}_{2} \mathrm{Cl}_{2}$ solution to avoid the formation of homopolymers. The polymers were finally dried over vacuum at $45^{\circ} \mathrm{C}$ to constant weight. The amounts of monomeric units in the copolymers were determined by elemental analysis. Reactivity ratios $r_{1}$ for the classical copolymerization model were determined using the linearization methods of Finemann-Ross (FR method) and Kelen-Tüdös(KT method) $(27,28)$.

\subsection{Biological activity of the polymers}

The antibacterial screening was carried out using the disc diffusion method as described by Bauer et al. (29), with some modifications.

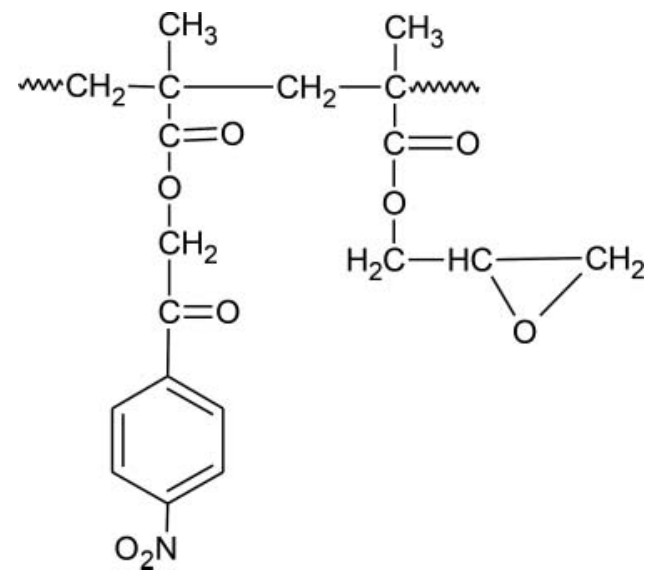

Scheme 1. The structure of the copolymers.
The test bacteria were inoculated into tubes of nutrient broth separately and incubated at $37^{\circ} \mathrm{C}$ for $18 \mathrm{~h}$. Each of the cultures was then adjusted to $0.5 \mathrm{McFarland}$ turbidity standard and inoculated (0.2 $\mathrm{ml}$ each) onto Nutrient agar plates. A sterile 6-mm paper disc was impregnated with test material (homopolymers and copolymers) (100 $\mu \mathrm{g} /$ disk) after dissolving it in solvents (DMSO) under aseptic conditions. The discs were placed on the bacterial lawn of agar plates. All tests were performed in duplicate.The zones of inhibition of microorganism growth of the standard samples polymers were measured with a millimeter ruler at the end of the incubation period. The aminoglycoside antimicrobial agent amikacin $(10 \mu \mathrm{g} /$ disk) and its solvents were used as positive and negative controls, respectively.

\section{Results and discussion}

\subsection{Spectroscopic characterization of the poly(NFM)}

The FT-IR spectrum of poly(NFM) are seen in Figure 1A. The FTIR spectrum of poly(NFM) shows a peak at 3103 and $3075 \mathrm{~cm}^{-1}$ due to the $\mathrm{C}-\mathrm{H}$ stretching of the aromatic ring. The peaks at 3000 , 2942 and $2839 \mathrm{~cm}^{-1}$ are attributed to the unsymmetrical and symmetrical C-H stretching of methylene and methyl groups. The ester and ketone carbonyl stretching is observed at 1741 and 1734 $\mathrm{cm}^{-1}$ respectively. The ring stretching vibrations of the aromatic nuclei observed at 1616,1512 and $1478 \mathrm{~cm}^{-1}$. The symmetrical bending vibrations of methyl group are seen at $1390 \mathrm{~cm}^{-1}$. The peak at $1155 \mathrm{~cm}^{-1}$ corresponds to the $\mathrm{C}-\mathrm{O}$ stretching. The $\mathrm{C}-\mathrm{H}$ out of plane bending vibrations of the trisubstituted aromatic nuclei is observed at 828 and $741 \mathrm{~cm}^{-1}$. The ${ }^{1} \mathrm{H}-\mathrm{NMR}$ spectrum of poly (NFM) shows a resonance signal at 6.15-6.27 ppm corresponds to the aromatic protons. The methylenoxy group $\left(\mathrm{OCH}_{2}\right)$ show a signal at $5.24 \mathrm{ppm}$. The broad resonance signal between 1.89 and $1.06 \mathrm{ppm}$ is due to backbone methylene and $\alpha$-methyl group. In the proton decoupled ${ }^{13} \mathrm{C}-\mathrm{NMR}$ spectrum of poly(NFM), the ester carbonyl carbon shows a signal at $176.83 \mathrm{ppm}$. The aromatic carbon attached to the oxygen atom gave signal at $151.12 \mathrm{ppm}$. The other aromatic carbons gave signals at 129.60, 121.98 and $100.20 \mathrm{ppm}$. The backbone methylene and tertiary carbons gave signals at 52.01 and $45.72 \mathrm{ppm}$. The peak at $56.94 \mathrm{ppm}$ is attributed to the methylenoxy groups and that at $18.50 \mathrm{ppm}$ is due to the $\alpha$-methyl group.

\subsection{Characterization of the copolymers}

\subsubsection{Solubility}

The solubility of the homopolymers and copolymers was tested via the mixing of $10 \mathrm{mg}$ of each polymer with $3 \mathrm{ml}$ of various solvents in test tubes. After the closed tubes were set aside for 1 day, the solubility was observed. The homopolymers and copolymers were soluble in 1,4-dioxane, dichloromethane, dimethylacetamide, dimethylformamide, dimethyl sulfoxide, tetrahydrofuran, but were insoluble in n-hexane, n-heptane, ethanol, and methanol solvents.

\subsection{FTIR spectrum}

The FT-IR spectrum of the poly(NFM-co-GMA) (0.47:0.53) are shown in Figure 1B. The FT-IR data confirms the formation of 


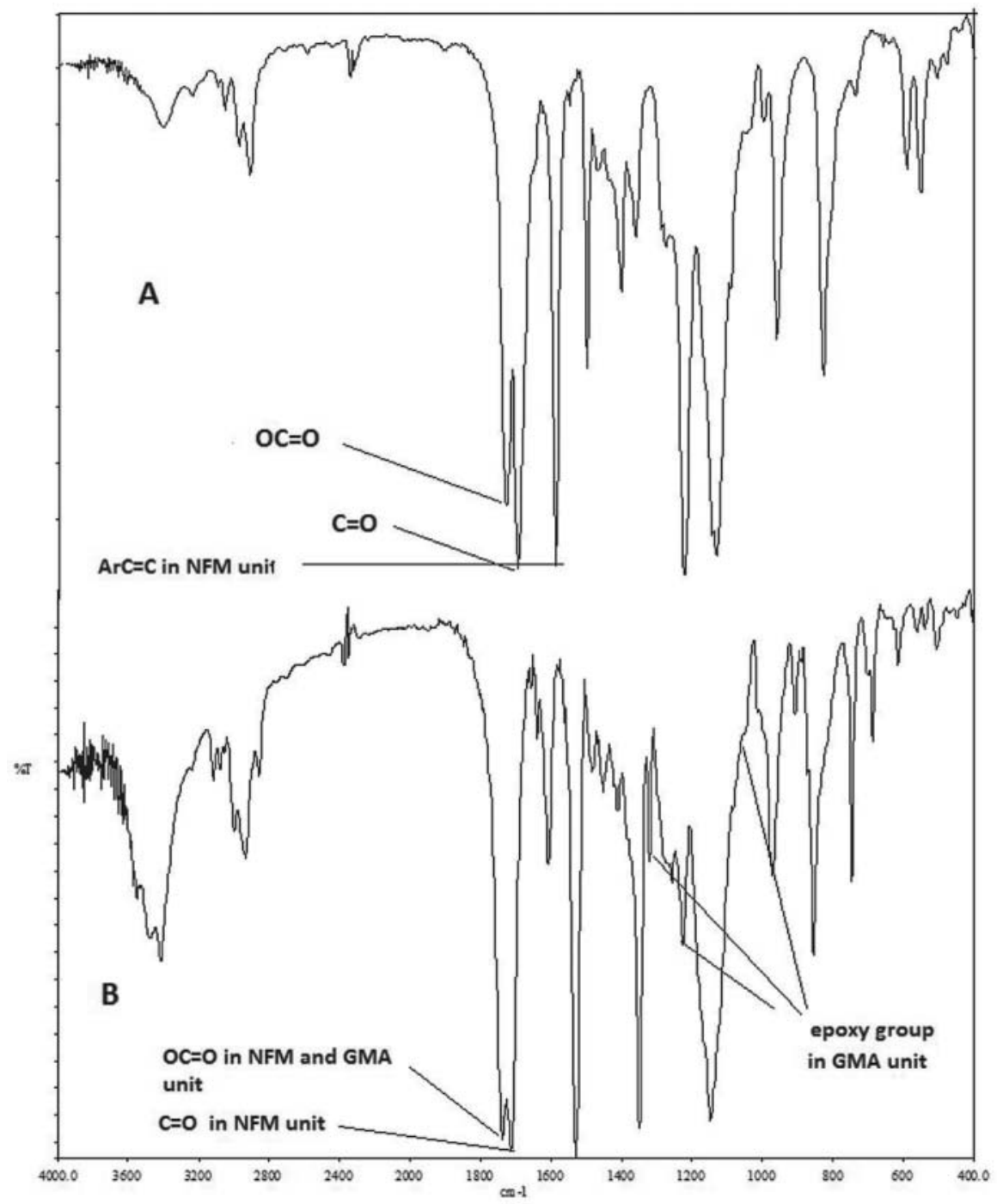

Figure 1. FTIR spectrum of poly(NFM) (A) and poly(NFM-co-GMA)(B) with molar fraction of NFM 0.47.

the copolymer structure. It shows a peak at 3103 and 3006 $\mathrm{cm}^{-1}$ corresponding to the $\mathrm{C}-\mathrm{H}$ stretching of the aromatic system in copolymer. The symmetrical and asymmetrical stretching due to the methyl and methylene groups is observed at 3000,2944 and $2841 \mathrm{~cm}^{-1}$. The peaks at about $1739 \mathrm{~cm}^{-1}$ are attributed to the ester carbonyl stretchings of NFM and GMA units. The ketone carbonyl peak of NFM units are seen at 1725 $\mathrm{cm}^{-1}$. The aromatic $\mathrm{C}=\mathrm{C}$ stretching is observed at 1616,1580 and $1477 \mathrm{~cm}^{-1}$. The out of plane bending vibration of aromatic $\mathrm{C}=\mathrm{C}$ is seen at $683 \mathrm{~cm}^{-1}$. The ether link due to the $\mathrm{OCH}_{2}$ group, $\mathrm{C}-\mathrm{O}$ link in the ester of NFM units and the C-O link in the ester of GMA units show signals at 1153,1270 and 1340 $\mathrm{cm}^{-1}$, respectively. The $\mathrm{C}-\mathrm{H}$ out of plane bending vibrations of the aromatic nuclei is observed at 840 and $759 \mathrm{~cm}^{-1}$. The characteristic peaks at for GMA units $1250,905,842 \mathrm{~cm}^{-1}$ correspond to the characteristic peaks of the epoxy group. Similar characteristic peaks were observed by other researchers $(30,31)$.

\subsection{NMR spectra}

The ${ }^{1} \mathrm{H}$-NMR and ${ }^{13} \mathrm{C}$-NMR spectra of the same copolymer are shown in Figures 2A and 2B. Both spectra of copolymer reveal the characteristic resonances corresponding to the general formula. All chemical shift data are also in agreement with the given molecular structure.

\subsection{Molecular weights of the polymers}

The molecular weights of the polymers were determined by GPC with polystyrene as the standard and tetrahydrofuran as solvent.The values of $M_{n}$ of poly(NFM-co-GMA) vary in the range from 15,500 to 18,700 and polydispersity index of copolymers lies in the range 1.57-1.89. The molecular weight characteristics of polymers are presented in Table 1.

\subsection{Determniation of the monomers reactivity ratios}

The reactivity ratios of the monomers were determined by the application of Fineman-Ross and Kelen-Tudos methods; the values of comonomer feed and copolymer composition are given in Table 2, while corresponding plots are presented in Figure 3, whereas the reactivity ratios are presented as follows: $r_{\mathrm{NFM}}=0.57$ and $r_{\mathrm{GMA}}=0.49$ (Fineman-Ross method), $r_{\mathrm{NFM}}=0.69$ and $r_{\mathrm{GMA}}=0.60$ (Kelen-Tudos method). 

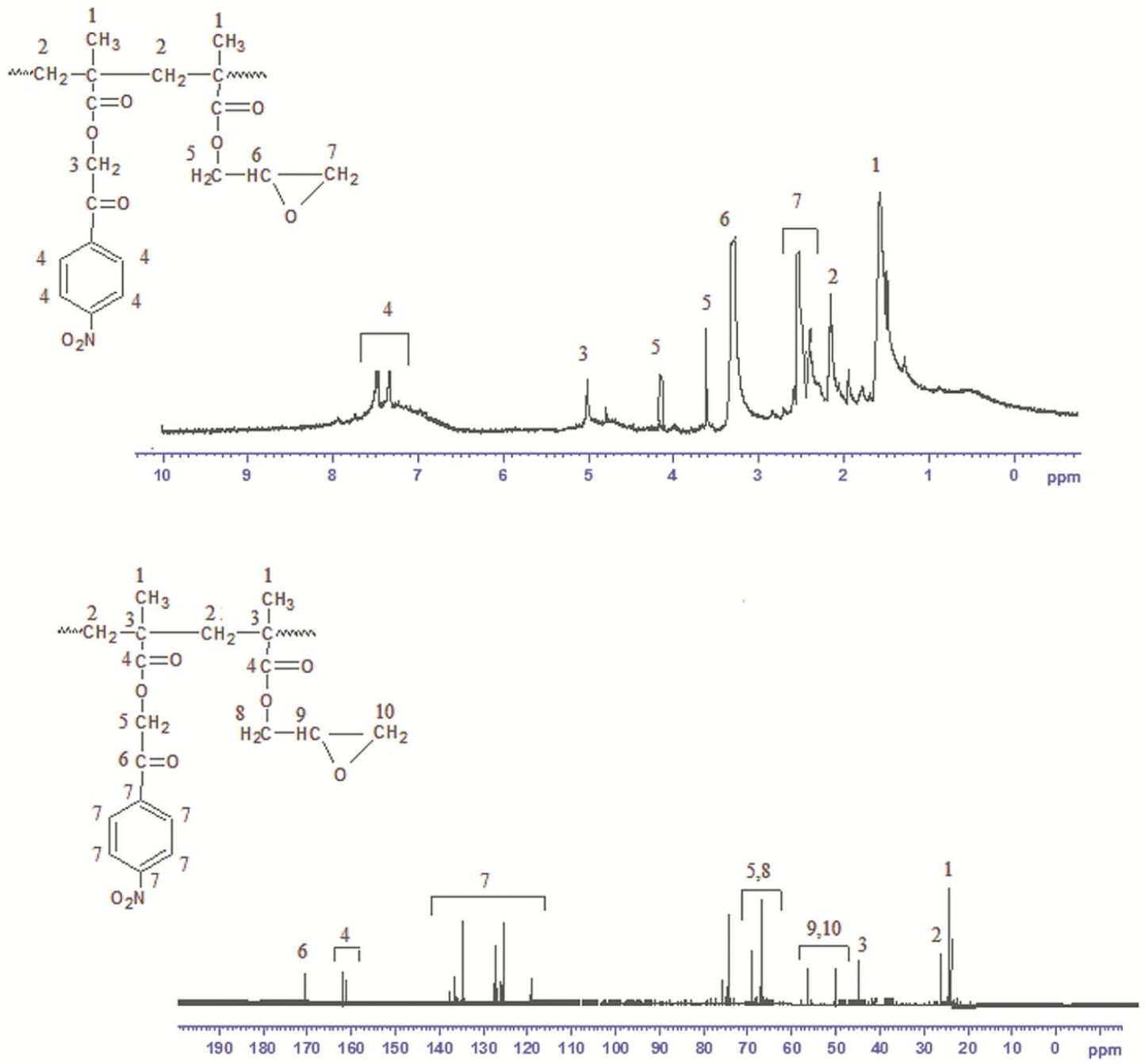

Figure 2. ${ }^{1} \mathrm{H}-\mathrm{NMR}(\mathrm{A})$ and ${ }^{13} \mathrm{C}-\mathrm{NMR}$ (B) spectraof poly(NFM-CO-GMA)with molar fraction of NFM 0.47 .

\begin{tabular}{lccccc}
\hline Methods & $\mathrm{r}_{1}$ & $\mathrm{r}_{2}$ & $\mathrm{r}_{1} \mathrm{r}_{2}$ & $1 / \mathrm{r}_{1}$ & $1 / \mathrm{r}_{2}$ \\
\hline F-R & 0.57 & 0.49 & 0.28 & 1.75 & 2.04 \\
K-T & 0.69 & 0.60 & 0.41 & 1.44 & 1.67 \\
\hline
\end{tabular}

polymer chain is random although there is a possible tendency for alternation. Similar results have been confirmed by other researchers $(32,33)$.

In all the cases, the plots were linear indicating that these copolymerizations follow the conventional copolymerization kinetics and that the reactivity of a polymer radical is determined only by the terminal monomer unit. As is seen, NFM is more active in copolymerization comparing to GMA; both $r_{\mathrm{NFM}}$ and $r_{\mathrm{GMA}}$ are less than 1, so monomer distribution in

Table 1. Molecular weights of Poly(NFM-co-GMA).

\begin{tabular}{lll}
\hline$F_{\mathrm{NFM}}{ }^{\mathrm{a}}$ & $M_{n} \times 10^{-4}$ & $M_{\mathrm{w}} / M_{n}$ \\
\hline 0.26 & 1.87 & 1.89 \\
0.34 & 1.83 & 1.85 \\
0.42 & 1.74 & 1.80 \\
0.50 & 1.65 & 1.72 \\
0.61 & 1.63 & 1.68 \\
0.67 & 1.58 & 1.63 \\
0.74 & 1.55 & 1.57 \\
\hline
\end{tabular}

${ }^{\mathrm{a}} F_{\mathrm{NFM}}$ is the mole fraction of NFM in the copolymer.

\subsection{Tg values of the polymers}

The pure Poly (NFM) and Poly (GMA) show single glass-transition temperatures at about 101 and $74^{\circ} \mathrm{C}$, respectively. In comparison to that of poly (GMA), the shift to higher temperature is also noted for all the copolymers studied and its

Table 2. Monomer compositions in feed and in the copolymer.

\begin{tabular}{|c|c|c|c|c|c|c|}
\hline \multirow[b]{2}{*}{ Sample } & \multicolumn{2}{|c|}{$\begin{array}{l}\text { Feed composition } \\
\text { (mol fraction) }\end{array}$} & \multirow[b]{2}{*}{ Conv. (\%) } & \multirow[b]{2}{*}{ N \% } & \multicolumn{2}{|c|}{$\begin{array}{l}\text { Copolymer composition } \\
\text { (mol fraction) }\end{array}$} \\
\hline & NFM & GMA & & & NFM & GMA \\
\hline 1 & 0.20 & 0.80 & 8.50 & 2.16 & 0.26 & 0.74 \\
\hline 2 & 0.30 & 0.70 & 9.50 & 2.67 & 0.34 & 0.66 \\
\hline 3 & 0.40 & 0.60 & 9.70 & 3.17 & 0.42 & 0.58 \\
\hline 4 & 0.50 & 0.50 & 8.60 & 3.59 & 0.50 & 0.50 \\
\hline 5 & 0.60 & 0.40 & 9.75 & 4.16 & 0.61 & 0.39 \\
\hline 6 & 0.70 & 0.30 & 8.70 & 4.41 & 0.67 & 0.33 \\
\hline 7 & 0.80 & 0.20 & 9.50 & 4.76 & 0.74 & 0.26 \\
\hline
\end{tabular}



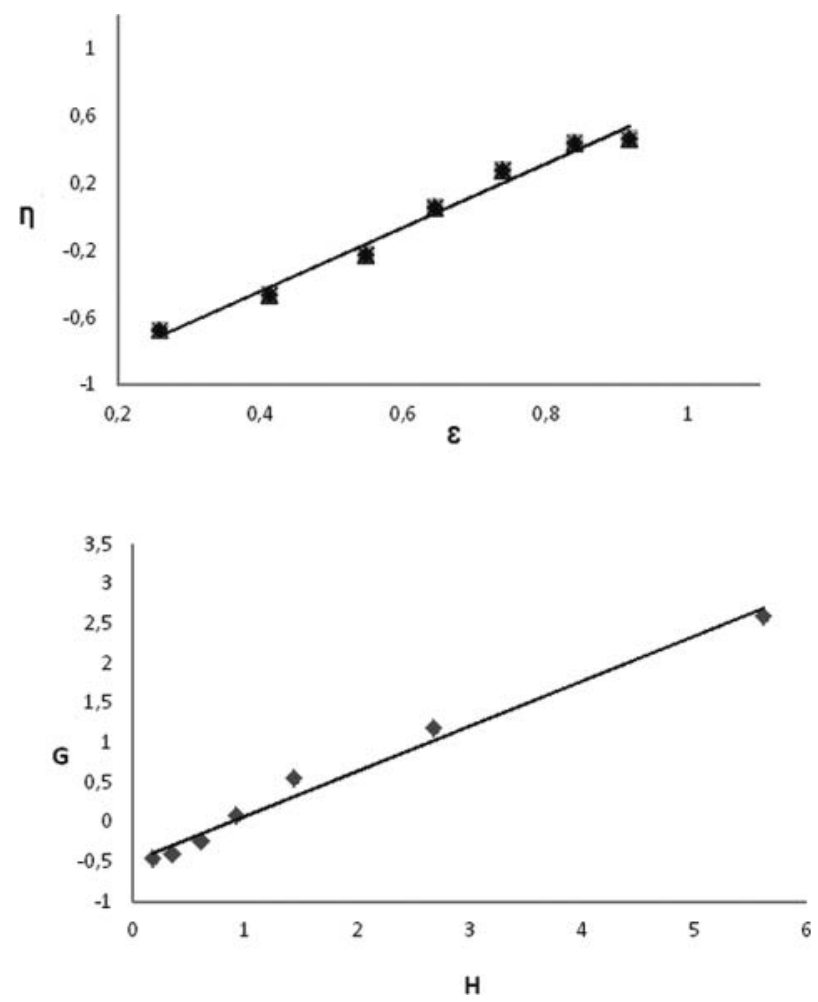

Figure 3. FR plots and KT plots for determining the monomer reactivity ratios in the copolymerization of NFM $\left(M_{1}\right)$ and GMA $\left(M_{2}\right)$.

magnitude is dependent on the increasing in NFM molar fraction in the copolymer chain. The results clearly indicate that $\mathrm{Tg}$ values of copolymers depend on the composition of comonomers and increase with increasing NFM content in the polymer chain. This trend indicates the ideal mixing of the two components in this copolymer system, and the specific volumes for the copolymers are similar to that for ideal mixing, and the free volume in poly(GMA) was higher than that in poly(NFM). The $\mathrm{Tg}$ values of copolymers are between those of the corresponding homopolymers. These values are indicated in Table 3.

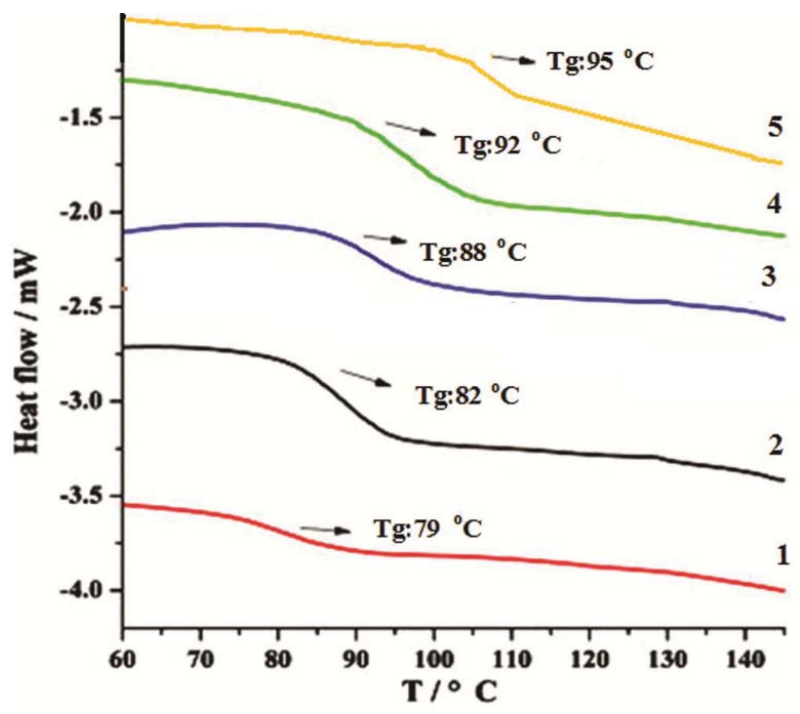

Figure 4. DSC curves of copolymers for $26 \%$ NFM (1), $34 \%$ NFM (2), $50 \%$ NFM (3), 61\% NFM (4), 65\% NFM (5).
Table 3. Comparison of observed Tg value of copolymers with calculated $\mathrm{Tg}$ value from Fox and Gibbs-Di Marzio equations.

\begin{tabular}{lcccc}
\hline Sample & $\mathrm{W}_{1}{ }^{\mathrm{a}}$ & $\mathrm{Tg}\left({ }^{\circ} \mathrm{C}\right)^{\mathrm{b}}$ & $\mathrm{Tg}\left({ }^{\circ} \mathrm{C}\right)^{\mathrm{c}}$ & $\mathrm{Tg}\left({ }^{\circ} \mathrm{C}\right)^{\mathrm{d}}$ \\
\hline GMA & 100 & 74 & 74 & 74 \\
1 & 26 & 80 & 81 & 79 \\
2 & 34 & 81 & 83 & 82 \\
3 & 42 & 83 & 85 & 85 \\
4 & 50 & 85 & 88 & 88 \\
5 & 61 & 89 & 91 & 92 \\
6 & 67 & 90 & 92 & 95 \\
7 & 74 & 93 & 94 & 99 \\
NFM & 100 & 101 & 101 & 101 \\
\hline
\end{tabular}

${ }^{a}$ Weight fraction of NFM in the copolymer.

${ }^{\mathrm{b}}$ Calculated by Fox equation.

'Calculated by Gibbs-Di Marzio equation.

${ }^{\mathrm{d} O b s e r v e d ~ i n ~ r e l a t i n g ~ D S C ~ c u r v e . ~}$

The simplest equation describing the effect of composition on $T_{g}$ is the Gibbs-Di Marzio equation (34):

$$
T_{g}=\Phi_{N F M} T_{g N F M}+\Phi_{G M A} T_{g G M A},
$$

where $\Phi_{\mathrm{NFM}}, \Phi_{\mathrm{GMA}}$ are the mole fractions of NFM and GMA, respectively in the copolymer and $\mathrm{T}_{g, \mathrm{NFM}}, \mathrm{T}_{g, \mathrm{GMA}}$ are the glass transition temperatures of homopolymers, respectively.

A similar relationship was introduced by Fox (35):

$$
\frac{1}{T g}=\frac{W_{N F M}}{T g_{N F M}}+\frac{W_{G M A}}{T g_{G M A}}
$$

where $\mathrm{W}_{N F M}$ and $\mathrm{W}_{G M A}$ are the weight fractions of NFM and GMA in the copolymer. As is seen in Table 3, large positive deviations are obtained by these two methods because they are based only on thermodynamic and free volume theories of the glass transition and they do not take into consideration the monomer sequence distribution and the effect of their compatibility on steric and energetic interactions. Therefore, several models have been proposed that take into account these considerations. DSC curves for some copolymers are shown in Figure 4 .

\subsection{Thermal stability of the polymers}

The results of TGA analysis of homo- and copolymers are compared in Table 4. The initial decomposition temperatures of poly(NFM) and poly(GMA) are around 241 and $184^{\circ} \mathrm{C}$, respectively. The degradation of poly(NFM) occurred in two stages.

Table 4. Some TGA results of the copolymers.

\begin{tabular}{lccccc}
\hline & & \multicolumn{3}{c}{$\begin{array}{c}\text { Temperature }\left({ }^{\circ} \mathrm{C}\right) \text { for } \\
\text { a Weight Loss of }\end{array}$} & $\begin{array}{c}\text { Residue (\%) } \\
\text { at } 450^{\circ} \mathrm{C}\end{array}$ \\
\cline { 3 - 5 } Polymer & IDT (\%) & 10 & 35 & 50 & \\
\hline Poly(NFM) & 241 & 271 & 342 & 380 & 46 \\
Poly(GMA) & 184 & 205 & 233 & 246 & 2 \\
Poly(NFM-Co-GMA) & & & & & 33 \\
$(74 / 26)$ & 213 & 228 & 302 & 331 & 22 \\
$(50 / 50)$ & 201 & 222 & 286 & 340 & 12 \\
$(26 / 74)$ & 189 & 213 & 255 & 290 & \\
\hline
\end{tabular}

anitial decomposition temperature. 


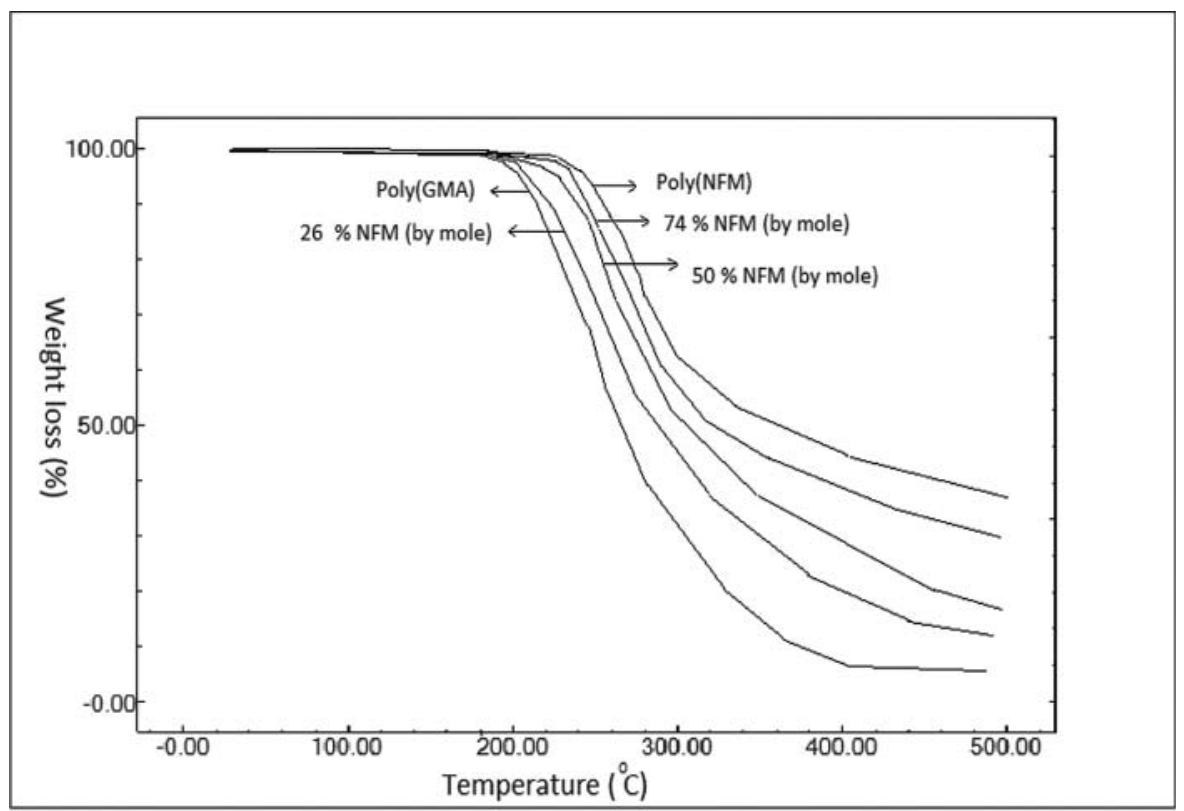

Figure 5. TGA curves for homoplymers and some copolymers.

The first stage was observed at $241-301{ }^{\circ} \mathrm{C}$. The second stage decomposition commenced at $305-364^{\circ} \mathrm{C}$. The TG/DTGDTA curves of copolymers showed that the thermal decomposition took place mainly in two stages and it is understood from TG/DTG curves, the first and second decomposition temperatures for copolymers are in range of $195-330^{\circ} \mathrm{C}$ and $335-$ $470^{\circ} \mathrm{C}$, respectively. Some degradation characteristics of the copolymers are given in Table 4 by comparison with those of the homopolymers. The thermal stabilities of copolymers are between those of the corresponding homopolymers.TGA curves for poly(NFM), poly(GMA) and three copolymers are shown in Figure 5.

Thermal degradation of poly(GMA) proceeds in two steps. The first depolymerization mainly starts at the unsaturated chain ends followed by random chain scission at higher temperature. The results are consistent with the literature (36).

Thus, the thermal stability of the copolymers was improved by the incorporation of NFM. The initial decomposition temperatures of the copolymers were between those of the homopolymers. The thermal degradation of poly- $n$-alkyl methacrylates typically produces the monomer as a result of depolymerization $(37,38)$. The formation of cyclic anhydride type structures by intramolecular cyclisation is another main process in degradation of these polymers. The latter produces some low molecular weight products, depending on the chemical structures of the side chain of poly-methacrylic esters. The increasing thermal stability at higher temperatures may probably be because of the presence of bromophenyl group and epoxy groups in the side chain, which form cross-links.

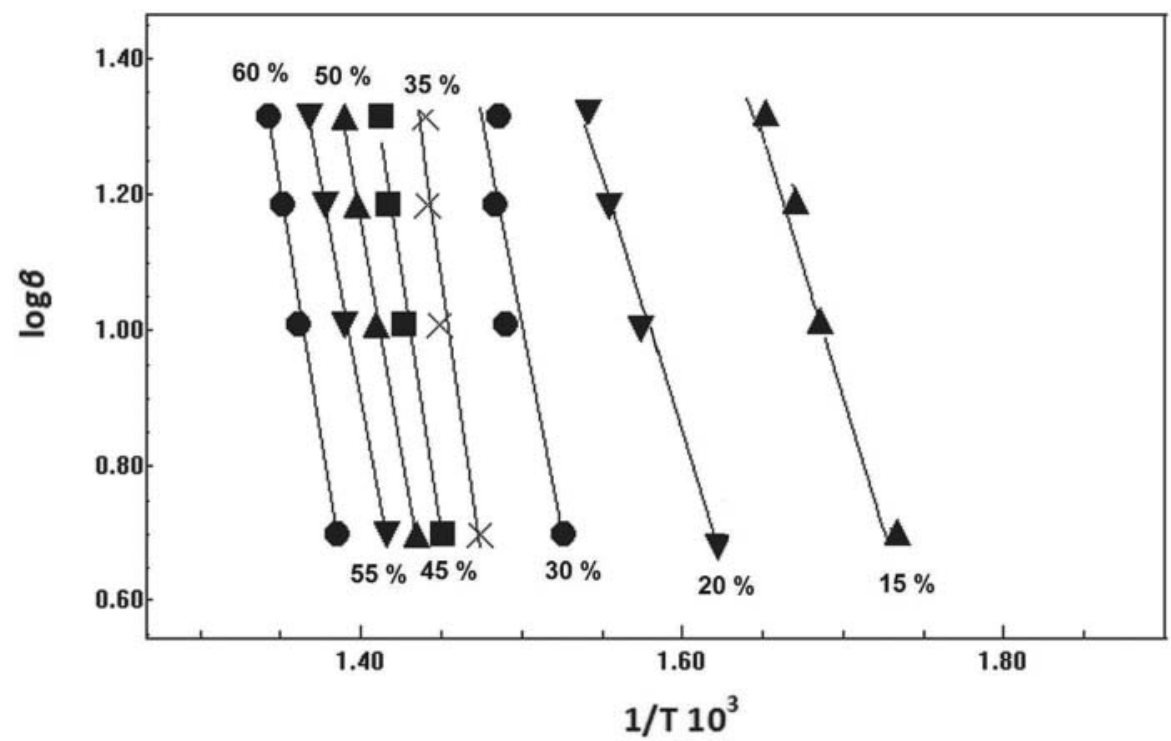

Figure 6. Ozawa's plots of logarithm of heating rate $(\beta)$ vs. reciprocal temperature $(1 / T)$ at different conversions for poly(NFM-co-GMA)(26:74) 
Table 5. The apparent activation energies of investigated copolymers under thermal degradation in $\mathrm{N}_{2}$.

\begin{tabular}{|c|c|c|c|c|c|c|c|c|c|}
\hline \multicolumn{10}{|c|}{ Activation Energy ( $\mathrm{kJ} / \mathrm{mol}$ ) Conversion (\%) } \\
\hline Poly(NFM) & 111.9 & 113,6 & 132.9 & 151.1 & 147.1 & 147.5 & 166.9 & 165.5 & 169.1 \\
\hline Poly(NFM26\%-co-GMA) & 98.4 & 118.1 & 116.2 & 137.0 & 112.8 & 115.4 & 115.0 & 123.3 & 147.5 \\
\hline Poly(NFM42\%-co- GMA) & 125.9 & 129.0 & 138.4 & 119.4 & 144.1 & 114.4 & 128.5 & 114.6 & 135.8 \\
\hline Poly(NFM50\%-co- GMA) & 129.2 & 115.2 & 125.3 & 136.2 & 145.5 & 129.0 & 153.0 & 148.3 & 161.6 \\
\hline Poly(NFM61\%-co- GMA) & 135.1 & 138.5 & 122.5 & 124.9 & 147.2 & 178.1 & 135.8 & 151.7 & 148.9 \\
\hline
\end{tabular}

\subsection{Decomposition kinetics of the polymers}

The degradation parameters of polymers were estimated by dynamic thermogravimetric analysis in nitrogen of the polymers has been performed at various heating rates $7,10,15$ and $20^{\circ} \mathrm{C} / \mathrm{min}$. The thermal degradation expression results are influenced by different assumptions and derivatives, for example, bulk or powder, carrier gas, flow rate, would directly affect the results of parameters.

According to the method of Ozawa (39) the apparent thermal decomposition activation energy, Ea, can be determined from the TGA thermograms under various heating rates according to the following equation:

$$
E_{a}=-\frac{R}{b}\left[\frac{d \log \beta}{d(1 / T)}\right]
$$

where $R$ is the gas constant; $b$ is the constant (0.4567); and $\beta$ is the heating rate $\left({ }^{\circ} \mathrm{C} / \mathrm{min}\right)$. Hence, the activation energy of degradation can be determined from the slope of the linear relationship between $\log \beta$ and $1 / T$. The results of the Ozawa analysis for poly(NFM-co-GMA)(26:74) are given in Figure 6, which shows that the best fitting straight lines are nearly parallel, indicating a constant activation energy range of conversions analyzed and confirming the validity of the approach used. Activation energies corresponding to the different conversions are listed in Table 5. Ea calculated from the Ozawa method is superior to other methods for complex degradation, since it does not use the reaction order in the calculation of the decomposition activation energy.

Alternatively, The Ea values of the polymers have been obtained according to the Kissinger (40) method without precise knowledge of the reaction mechanism, using the
Equation 5.

$$
\frac{d\left(\ln \left(\beta / T_{p}^{2}\right)\right)}{d\left(1 / T_{p}\right)}=-\frac{E_{a}}{R}
$$

where $\beta$ is the heating rate, Tp is the maximum temperature and $R$ is the ideal gas constant. From a plot of $\ln \left(\beta / T_{p}^{2}\right)$ vs.1/ $T_{p}$ and fitting to a straight line, the activation energy $E_{\mathrm{a}}$ can be calculated from the slope. The mean activation energies related to the thermal decomposition of first and second stages of poly (NFM-co-GMA)(26:74) by using Kissinger method in $\mathrm{N}_{2}$ was found to be 109.3, and $111.5 \mathrm{~kJ} / \mathrm{mol}$, respectively. The Ea values for the polymers are given in Table 6 .

\subsection{Photophysical properties of the polymers}

The photostability of the copolymers were investigated by UVspectrophotometry. A solution of polymers in $\mathrm{CH}_{2} \mathrm{Cl}_{2}$ was cast onto a quartz glass plate with a spin coater and then was annealed for $30 \mathrm{~min}$ at $40^{\circ} \mathrm{C}$. The polymer films were irradiated with a $500-\mathrm{W}$, high-pressure mercury lamp at $254 \mathrm{~nm}$. The films of polymers were exposed to UV light and, as expected, all of them presented alteration in the FTIR spectra as a function of time. The discussion of the results will focus on the absorption evolution in the $\mathrm{C}=\mathrm{O}$ stretching range (assigned to carbonyls), close to $1740 \mathrm{~cm}^{-1}$. After irradiation for 6, 24, 12 and, $24 \mathrm{~h}$, the FTIR spectra of the polymers showed changes. A new band as a shoulder at $1710 \mathrm{~cm}^{-1}$ was observed in the spectra of the polymers. Also, the absorbance of the shoulder at $1710 \mathrm{~cm}^{-1}$ increased relatively as that of the band at about $1740 \mathrm{~cm}^{-1}$ decreased from 12 to $24 \mathrm{~h}$. In addition, although all of the polymers were soluble in $\mathrm{CH}_{2} \mathrm{Cl}_{2}, \mathrm{CHCl}_{3}$, dimethylformamide, DMSO, 1,4-dioxane, and so forth, not one of the polymers was soluble in any solvent after irradiation. Although a

\begin{tabular}{|c|c|c|c|c|c|}
\hline \multirow[b]{2}{*}{ Polymer } & \multicolumn{2}{|c|}{$1^{\text {st }}$ stages } & \multicolumn{2}{|c|}{$2^{\text {nd }}$ stages } & \multirow[b]{2}{*}{$\mathrm{R}$} \\
\hline & TG range $\left({ }^{\circ} \mathrm{C}\right)$ & $\mathrm{Ea}(\mathrm{kj} / \mathrm{mol})$ & TG range $\left({ }^{\circ} \mathrm{C}\right)$ & $\mathrm{Ea}(\mathrm{kj} / \mathrm{mol})$ & \\
\hline Poly(NFM) & $282-341$ & 125.7 & $341-445$ & 177.2 & 0.99 \\
\hline Poly(NFM26\%-co-GMA) & $279-346$ & 109.3 & $345-455$ & 111.5 & 0.98 \\
\hline Poly(NFM34\%-co- GMA) & $274-352$ & 124.2 & $351-469$ & 116.6 & 0.99 \\
\hline Poly(NFM42\%-Co- GMA) & $269-355$ & 133.5 & $355-451$ & 129.6 & 0.99 \\
\hline Poly(NFM50\%-co- GMA) & $272-351$ & 179.7 & $353-455$ & 191.5 & 0.99 \\
\hline Poly(NFM61\%-co- GMA) & $269-349$ & 149.6 & $345-459$ & 179.6 & 0.98 \\
\hline Poly(NFM67\%-co- GMA) & $266-345$ & 138.1 & $346-465$ & 134.3 & 0.99 \\
\hline Poly(NFM74\%-co- GMA) & $263-355$ & 135.9 & $347-453$ & 196.1 & 0.98 \\
\hline
\end{tabular}

Table 6. Regression coefficients and degradation apparent activation energies (Ea) by Kissinger equation for copolymers and NFM and GMA homopolymers. 


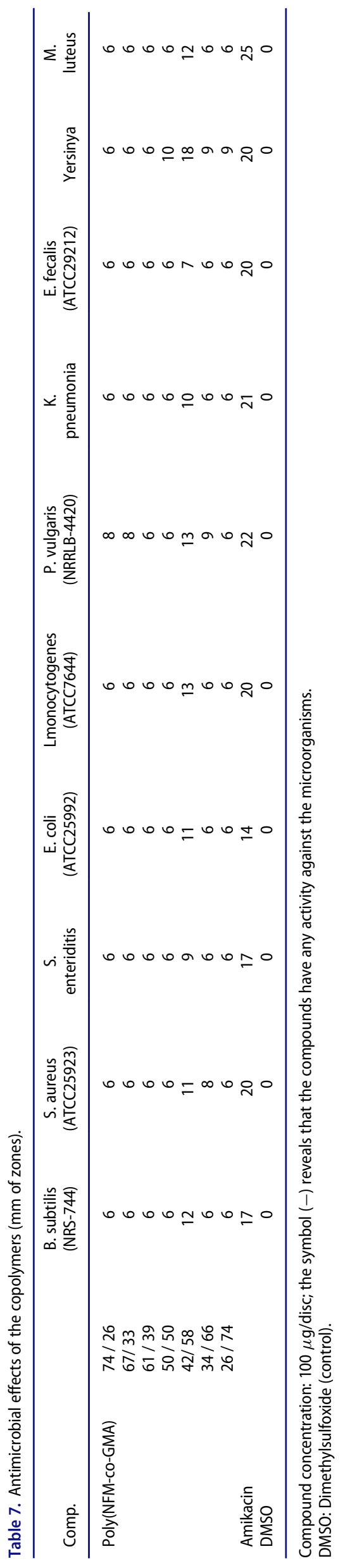




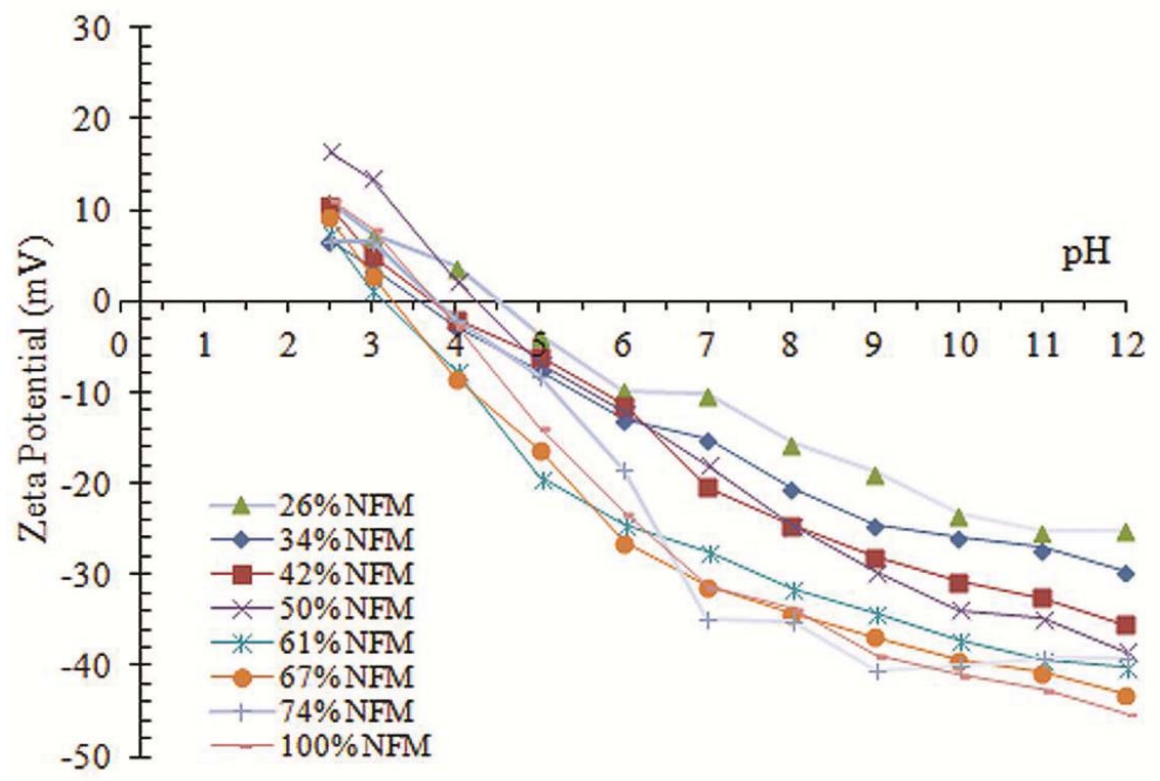

Figure 7. Zeta potential vs. pH curves of polymers (Note: Natural pH of polymer suspensions are between 6.5 and 7).

practical evaluation from spectral data is rather dubious because the sensitivity of photocross-linkable polymers is a function of the $\mathrm{Tg}$, molecular weight, polymer solubility, and so forth, the discrimination of photoresponsibilities of the chromophores themselves is possible to a certain extent. To achieve a highly integrated chromophore system, an arrangement of the chromophores in a first-order structure of a polymer is not enough; one should resort to a higher order structure formed by the polymer (41). In this context, a number of studies have focused on amphiphilic polyelectrolytes carrying aromatic chromophores as pendant groups (36). The amphiphilic polyelectrolyte loadings are high enough that the hydrophobic chromophores are forced to be densely packed in an aqueous solution (42). All the experimental datas indicate that photodegradation in the carbonyl region occurred and crosslinking followed. Some polymers with carbonyl side chains displayed photodegradation (43).

\subsection{Antimicrobial activity of the polymers}

The antimicrobial activity of polymers in general increases with increasing hydrophobic content in the side chains. This is likely because of the increased hydrophobicity of polymers enhancing insertion of polymers into the hydrophobic region of cell membranes. Our recent investigation on methacrylate polymers indicated that the hydrophobic side chains of methacrylate random copolymers are inserted into lipid bilayers (44).

The results showed that the investigated polymers have good biological activity but it was less comparable to that of standard drugs such as amikacin. The data reported in Table 7 are the average data of three experiments. Only, poly(NFM-co-GMA) (42/58) have good biological activity on all microorganisms compared to others polymers. However, its not clear why only this one showed more good antimicrobial acitivity, but as more data are collected in the literature, it becomes clearer what may be the biological sequelae of a given substitution pattern. It has been suggested that copolymers with $\mathrm{N}$, and $\mathrm{O}$ donor systems and the carbonyl groups might have inhibited enzyme production because enzymes that require a free hydroxy group for their activity appear to be especially susceptible to deactivation by the donor atoms of the polymers. The results are consistent with the literature $(45,46)$.

\subsection{Comparison of surface properties of polymers}

\subsection{1. $\mathrm{pH}$ dependent zeta potential curves (determination of iso electrical point)}

Zeta potential vs. $\mathrm{pH}$ curves of synthesized polymers are shown in Figure 7. It is seen that all polymers have negative surface charge at natural $\mathrm{pHs}(\mathrm{pH}$ 6.5-7.0). This situation can be

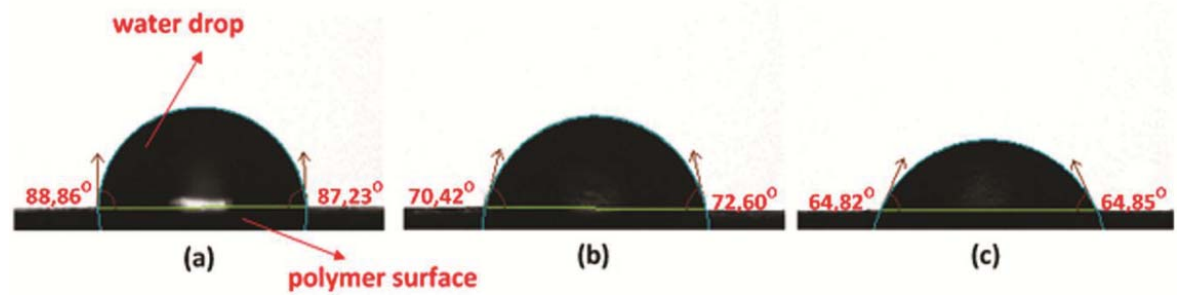

Figure 8. Contact angles of water drops on different polymer substrates which have (a) $26 \%$ NFM, (b) $50 \%$ NFM and (c) $10 \%$ NFM composition. 


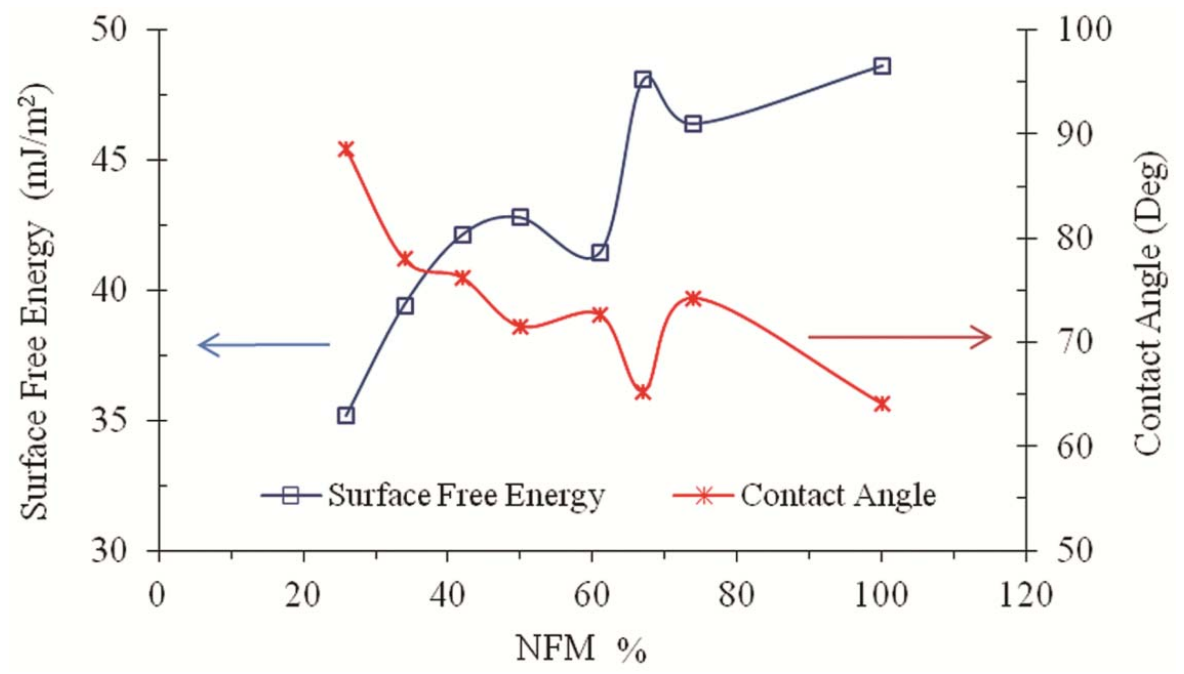

Figure 9. The effect of NFM ratio in polymer composition on contact angle with water and surface free energy of polymer.

explained by similar behavior of the structure like negatively charged materials due to high polarity of carbonyl $(\mathrm{C}=\mathrm{O})$ and nitro $\left(\mathrm{NO}_{2}\right)$ groups in polymer structure. Moreover, as clearly seen from the curves the iso electrical points (iep) of the polymers are between 3.2 and 4.5. These results are in accordance with the iep values determined for PMMA in the literature. The polymers are negatively charged at $\mathrm{pH}$ values over iep and positively charged at $\mathrm{pH}$ values below iep. Changes at zeta potentially dependent on $\mathrm{pH}$ can be explained by the adsorption of $\mathrm{OH}^{-}$and $\mathrm{H}_{3} \mathrm{O}^{+}$ions in the medium onto polar groups on polymers' surface (23). The figure also shows that zeta potential reaches more negative values with an increase at the amount of NFM monomer in copolymer. This can be explained by the presence of functional groups (i.e. carbonyl and nitro) with high polarity degree in NFM structure.

\subsubsection{Hydrophobicity and surface free energy depending on contact angle}

Contact angle measurement device is a simple, useful and sensitive tool for quantifying the wettability (or hydrophobicity) and the surface free energy of different materials in contact with water. Contact angles were measured with three different liquids (pure water, ethylene glycol, di-iodiomethane) to determine the hydrophobicity and to calculate surface free energy which are the other characteristics of synthesized polymers. Some photographs of the contact angles between water and polymers including $26 \%, 50 \%$ and $100 \%$ NFM are given in Figure 8. Here, it is seen that contact angle decreases (hydrophobicity decreases) with the increase in the percentage (\%) of NFM with high polarity in polymer.

The effect of NFM percentage in polymer on polymer's contact angle with water and on surface free energy is shown in Figure 9. Surface free energy and zeta potential are both related with surface chemistry and therefore it is mentioned that there is a correlation between these two characteristic specifications (47). Contact angle increased with the decrease of NFM ratio in polymer structure and reached to $88.6^{\circ}$ at $26 \%$ NFM while the contact angle was $64^{\circ}$ when the structure is consisted of $10 \%$ NFM. It is clearly seen that contact angle decreases and hydrophilicity increases with the increasing of NFM ratio in the structure. This is because of polar groups in NFM component of copolymer like carbonyl and nitro. Polar interactions between water drop and polymer surface becomes stronger because of these groups. Change at copolymer's surface free energy according to NFM ratio is given in Figure 9. As seen from Figure 9, surface free energy is increasing with the increase of NFM ratio and achieved $48,61 \mathrm{~mJ} / \mathrm{m}^{2}$ at $100 \%$ NFM while the surface free energy of polymer was $35,16 \mathrm{~mJ} / \mathrm{m}^{2}$ at $26 \% \mathrm{NFM}$. In other words, polar characteristic of copolymer increases with increasing of NFM amount and causing increase at surface free energy.

\section{Conclusions}

Copolymers of NFM with GMA have been prepared by radical polymerization in 1,4-dioxane at $65^{\circ} \mathrm{C}$. The reactivity ratios of the copolymers were estimated using linear graphical methods, and showed that a kinetic preference exists for the incorporation of NFM in the copolymer structure. The glass transition temperatures of the NFM with GMA copolymers were obtained and compared. The investigated polymers had the better antimicrobial activity, and it was less than the control group. The TGA studies revealed that the thermal stability of the copolymers increases with an increase of NFM in the copolymer chain. Finally, it was observed that the most of the synthesized polymers are not stable under near-UV irradiation. Surface properties of the polymers change according to their percentages in the structure. Zeta potential goes to more negative and iep shifts to lower $\mathrm{pH}$ with the increase of NFM ratio in polymer structure. Contact of polymer with water decreases (which means a decrease in hydrophobicity) with the increase of NFM ratio in polymer structure and depending on this, surface free energy increases as expected.

\section{Funding}

The authors wish to thank the financial support provided by the Afyon Kocatepe University Research Fund (Project No: 14-FENED-03). 


\section{References}

1. Arshady, R. (1992) J. Macromol. Sci. Rev. Macromol. Chem. Phys., C32: 101-132.

2. Erol, I. (2004) J. Polym. Sci. Pol. Chem., 42: 3157-3169.

3. Gerecht, S., Townsend, S.A., Pressler, H., Zhu, H., Nijst, C.L.E., Bruggeman, J.P., Nichol, J.W., Langer, R. (2007) Biomat., 28(32): 48264835 .

4. Lee, N.Y. (2013) Colloids and Surfaces B-Biointerfaces, 111: 313-320.

5. Pacansky, J., Waltman, R.J., Cox, R. (1991) Chem. Mater., 3(5): 903911.

6. Ueki, Y., Umemura, T., Li, J., Odake, T., Tsunoda, K. (2004) Anal. Chem., 76(23): 7007-7012.

7. Pérez, J.P., López-Cabarcos, E., López-Ruiz, B. (2006) Biomol. Eng., 23 (5): 233-245.

8. Klán, P., Šolomek, T., Bochet, C.G., Blanc, A., Givens, R., Rubina, M., Popik, V., Kostikov, A., Wirz, J. (2013) Chem. Rev., 113(1): 119-191.

9. Crivello, J.V. (2008) J. Polym. Sci. Part A: Polym. Chem., 46(11): 3820-3829.

10. Adachi, Y., Ooyama, Y., Shibayama, N., Ohshita, J. (2016) Dalton Trans., 45, 13817-13826.

11. Parker, S., Braden M. (1989) Biomaterials, 10: 91-95.

12. Chen, F.M., Zhao, Y.M., Zhang, R., Jin, F., Wu, Z.F., Jin, Y. (2006) Journal of Controlled Release, 114(2): 209-222.

13. Nicholson, J.W., Brookman, P.J., Lacy, O.M., Sayers, G.S., Wilson, A. D. (1998) J. Biomed. Mater. Res., 22: 623-631.

14. Gendy, T.S., Barakot, Y., Mohamed, A.I., Youssef, M. (1991) Polym. Int.,24: 235-240.

15. Mao, Y., Felix, N.M., Nguyen, P.T., Ober, C.K., Gleason, KK. (2006) Chem. Vap. Dep., 12(5), 259-262.

16. Feit, E.D., Wurtz, M.E., Kammlott, G.W. (1978) J. Vac. Sci. Technol., 15: 944-947.

17. Gunaydin, O., Yilmaz, F. (2007) Polymer Journal, 39(6): 579-588.

18. Leja, J., Surface chemistry of froth flotation, Plenum Press, New York (1982).

19. Good, R.J., Van Oss CJ., The modern theory of contact angles and hydrogen bond components of surface energies, in Modern approaches to wettability: Theory and application, Eds: Schared, M.E., Loeb, G., Plenum Press, New York (1992).

20. Yoon, R.H., Yordan, J.L. (1991) Journal of Colloid and Interface Science, 146(2): 101-108.
21. Kolluri, O.S., Plasma surface engineering of plastics: Surface Engineering, ASM Handbook, ASM International, USA. Vol. 5, 1994.

22. Żenkiewicz, M. (2007) Journal of Achievements in Materials and Manufacturing Engineering, 24(1): 137-145.

23. Falahati, H., Wong, L., Davarpanah, L., Garg, A., Schmitz, P., Barz D. P.J. (2014) Electrophoresis, 35(6): 870-872.

24. Abdollahi, M., Sharifpour, M. (2007) Polymer, 48(1): 25-30.

25. Abdollahi, H., Najavi, F., Ziaee, F., Kabiri, K., Narimani, F. (2014) Macromol. Res., 22(12): 1330-1336.

26. Erol, I., Cifci, C. (2011) Chin. J. Polym Sci., 29(1): 101-110.

27. Fineman, M., Ross, S.D.J. (1950) J. Polym. Sci.,5(2): 259-262.

28. Kelen, T., Tudos, F.J. (1975) J. Macromol. Sci. Chem.9: 1-27.

29. Bauer, A.W., Kirby, W.M., Sherris, J.C., Jurck, M. (1996) Am. J. Clin. Pathol., 451: 493-496.

30. Sokker, Y., Badawy, H., Zayed, E., Eldien, F., Farag, A. (2009) J. Hazard. Mater., 168: 137-144.

31. Wojnarovits, Z., Foldvary, Cs.M., Takacs, E. (2010) Radiat. Phys. Chem., 79(8): 848-862.

32. Gunaydin, O., Yilmaz, F. (2007) Polymer Journal, 39(6): 579-588.

33. Vijayanand, P.S., Kato, S., Satokawa, S., Kishimoto, M., Kojima, T. (2009) React. Funct. Polym. , 69(6): 333-340.

34. Dimarzio, E.A., Gibbs, J.H. (1963) J. Polym. Sci., 1: 1417-1428.

35. Fox, T.G., Flory, P.J. (1950) J. Appl. Phys. 21: 581-591.

36. Ahmad, S., Zulfiqar, S. (2002) Polym. Deg. Stab., 76: 173-177.

37. Erol, I., Soykan, C., Ilter, Z., Ahmedzade, M. (2003) Polym. Degrad. Stab., 81, 287

38. Coşkun, M., Soykan, C., Ahmedzade, M., Demirelli, K. (2001) Polym. Degrad. Stab., 72, 69.

39. Ozawa, T. (1965) Bul. Chem. Soc. Jpn., 38: 1881-1886.

40. Kissinger, H.E. (1957) Analytical Chemistry, 29: 1702-1706.

41. Guillet, J.E., Rendall, W. (1986) Macromolecules, 19: 224-230.

42. Morishima, Y., Itoh, Y., Nozakura, S. (1981) Macromol. Chem., 182 3135-3147.

43. Morishima, Y., Kobayash, T., Nozakura, S. (1989) Polym. J., 21: 267274.

44. Weir, N.A., Arct, J., Whiting, K. (1990) Eur. Polym. J. 26: 341-344.

45. Erol, I. (2008) J. Fluorine Chem., 129(7): 613-620.

46. Bonilla, A.M., Garcia, M.F. (2012) Prog. Polym. Sci., 37(2): 281-339.

47. Kolská, Z., Makajová, Z., Kolářová, K., Slepičková, N.K., Trostová, S., Řezníčková, A., Siegel, J., Švorčík, V. (2013) Polymer Science, Yilmaz F (Ed.).; ISBN: 978-953-51-0941-9, InTech, DOI: 10.5772/46144. 